\title{
Contribuições da análise microgenética às pesquisas em neurolinguística
}

\author{
Mirian Cazarotti Pacheco \\ Universidade Estadual de Campinas (UNICAMP), Campinas, São Paulo, Brasil \\ miriancpacheco@gmail.com
}

DOI: $\underline{\text { http://dx.doi.org/10.21165/el.v45i2.662 }}$

\begin{abstract}
Resumo
Este artigo visa analisar as contribuições do paradigma Microgenético para as teorias que fundamentam as pesquisas no campo da Neurolinguística de orientação enunciativo-discursiva. A forma de construção de dados nessas pesquisas focaliza a atenção a detalhes, o recorte de episódios interativos, um exame orientado para o funcionamento dos discursos e resulta num relato minucioso dos acontecimentos. A microgênese é proposta com vista aos demais domínios genéticos que focalizam o funcionamento linguístico-cognitivo dos sujeitos em todas as dimensões. A Análise Microgenética possibilitou demonstrar, neste estudo, que, a partir de dados singulares de sujeitos afásicos, podemos inferir sobre o funcionamento da linguagem e sua relação com a memória.
\end{abstract}

Palavras-chave: neurolinguística; análise microgenética; afasia.

\section{Contributions of microgenetic analysis to neurolinguistic research}

\begin{abstract}
This article aims to analyze the contributions of the microgenetic paradigm to theories underlying research in the field of Enunciative-Discursive Neurolinguistics. The way data are built in these studies focuses on details, sets of interactive episodes, and an oriented examination for the action of discourses. Then, this way results in a detailed report about the events of these research. The microgenesis is proposed in view of other genetic domains that focus on subjects' linguistic and cognitive operation in all dimensions. Microgenetic Analysis reveals that it is possible to infer, from single data of aphasic subjects, the functioning of language and its relation to memory.
\end{abstract}

Keywords: neurolinguistic; microgenetic analysis; aphasia.

\section{Introdução}

La elaboración del problema y del método se desarrollan conjuntamente, aunque no de un modo paralelo. La búsqueda del método se convierte en una de las tareas de mayor importancia en la investigación. El método, en este caso, es al mismo tiempo premisa y producto, herramienta y resultado de la investigación (VIGOTSKI, 2000, p. 47). 
Para Vigotski ${ }^{1}$ (2003, p. 86), principal representante da vertente sócio-históricocultural $^{2}$, à qual filiamos nossos estudos em Neurolinguística, "o método é, ao mesmo tempo, pré-requisito e produto, o instrumento e o resultado do estudo". A epígrafe acima foi escolhida para iniciar este trabalho, justamente porque a metodologia é um dos grandes desafios a serem enfrentados no campo dos estudos neurolinguísticos, pois influencia os recortes que fazemos dos fenômenos, as hipóteses teóricas e, principalmente, o acompanhamento terapêutico dos sujeitos, cuja linguagem se encontra impactada por alguma patologia - no qual se reflete, de fato, o resultado do estudo.

A partir de pressupostos vigotskianos, Freitas (2010) argumenta que a única opção coerente com a perspectiva sociocultural é a pesquisa qualitativa. Ao contrário das ciências naturais, cujo foco é um objeto do mundo - sobre o qual se fala - nas Ciências Humanas o objeto é o próprio homem. Não se fala sobre ele, mas com ele; busca-se compreender os significados construídos e compartilhados por sujeitos que se relacionam socialmente, ou seja, entender como as coisas acontecem, ao contrário de apenas constatar que acontecem. Em outras palavras, compreender processos e não produtos. Sendo assim, segundo a autora, não poderia ser pautada pelo critério da objetividade que respalda as Ciências Naturais. Baseando-se em Bakhtin, Freitas complementa dizendo que nas Ciências Humanas o investigador necessita travar uma relação dialógica com o pesquisado, não se limitando apenas a contemplá-lo.

Concordamos com a autora ao afirmar que é imprescindível que exista coerência entre o método e os princípios teóricos que orientam as pesquisas. Dentre as pesquisas de cunho qualitativo nas Ciências Humanas, são recorrentes aquelas que se respaldam, enquanto aspecto metodológico, no paradigma microgenético - originado nos trabalhos vigotskianos e, que também vem sendo mobilizadas no campo dos estudos neurolinguísticos de orientação enunciativo-discursiva.

Pretendemos, com este artigo, socializar parte do estudo realizado, em nível de pósdoutoramento $^{3}$, que teve dentre seus objetivos analisar as contribuições do paradigma Microgenético para as teorias que fundamentam as pesquisas no campo da Neurolinguística de orientação enunciativo-discursiva, por meio de investigação bibliográfica.

\section{Referenciais teóricos}

\section{A Neurolinguística de orientação enunciativo-discursiva e a pesquisa qualitativa}

De acordo com Góes (2000), quando Vigotski afirma que o método é simultaneamente o pré-requisito e o resultado do estudo, ele propõe diretrizes metodológicas, as quais procuram focalizar duas teses fundamentais: (i) a gênese das funções psicológicas

\footnotetext{
${ }^{1}$ Lev Semenovitch Vygotsky - sendo o sobrenome transliterado também como Vigotski, Vygotski ou Vigotsky - (1896-1934), foi um psicólogo bielo-russo que influenciou vários campos científicos.

${ }^{2}$ Também referida como sócio-his tórica ou his tórico-cultural.

${ }^{3}$ Cazarotti-Pacheco, 2015 (a referência completa encontra-se na Bibliografia).
} 
está nas relações sociais, (ii) a constituição do funcionamento humano é socialmente mediada, num curso de desenvolvimento que abrange evoluções e, principalmente, revoluções.

Vigotski (2003) postula que o objetivo das pesquisas em Ciências Humanas deve ser o de se analisar processos e não produtos (objetos). Para tanto, os pesquisadores devem se basear numa análise explicativa e não apenas descritiva de um fenômeno, que revele as relações dinâmicas ou causais subjacentes ao fenômeno, em contraponto à simples enumeração de características externas de um processo ${ }^{4}$. A análise explicativa "não rejeita a explicação das idiossincrasias fenotípicas correntes, mas, ao contrário, subordina-as à descoberta de sua origem real" (p. 84).

De acordo com Pereira (2010), Vigotski e Bakhtin têm em comum a fundamentação de suas teorias no materialismo histórico dialético e apesar de não terem proposto um "modo" de se fazer pesquisa, criticaram o reducionismo das concepções empiristas e idealistas que predominavam em seu tempo. Suas teorias foram construídas a partir da elaboração de uma síntese dialética entre objetividade e subjetividade, em que o sujeito é concebido em sua singularidade e é situado em relação ao seu contexto histórico e social. Ambos enfatizam o papel da linguagem, pois "é a linguagem que constitui o homem e sua consciência: um ser social, datado e marcado pela cultura de seu tempo" (PEREIRA, 2010, p. 54).

Freitas (2010) conclui que a pesquisa qualitativa apresenta-se como uma maneira diversa de se produzir conhecimento no campo das Ciências Humanas, cujo foco é o fenômeno em seu contexto real e esta é uma razão consideravelmente forte para fazê-la ser respeitada como ciência.

Novaes-Pinto (2012a, b) ${ }^{5}$ concorda com Damico et al. (1999) sobre as pesquisas qualitativas constituírem-se como um "feixe de práticas sistemáticas e interpretativas", por meio das quais respondemos a questões que se interessam por processos - em consonância com as proposições de Vigotski e de Freitas - para descobrir como as ações e as experiências sociais são criadas e mantidas. Trata-se de um paradigma complexo, com uma história longa e bem estabelecida, que vem sendo desenvolvido pela Sociologia e Antropologia desde as primeiras décadas do século XX, com o objetivo de estudar as culturas, sociedades e díades interacionais.

Podemos acrescentar, a esse respeito, os estudos na área da Neurolinguística de orientação enunciativo-discursiva que vem se desenvolvendo a partir dos trabalhos de Coudry (1988[1986]), filiados às abordagens sócio-histórico-culturais, com o objetivo de estudar tanto questões concernentes ao funcionamento cerebral, quanto ao funcionamento da linguagem. Esses trabalhos têm grande inspiração, principalmente, em Vigotski, Luria e Bakhtin, tanto aqueles que se referem às alterações decorrentes de lesões cerebrais - afasias, demências, epilepsias -, quanto os chamados atrasos de desenvolvimento e de aprendizagem $\mathrm{e}$, ainda, estudos que se interessam pelo funcionamento da linguagem fora do âmbito das patologias. Conceitos relativos a sujeito, processos dialógicos, processos de significação e

\footnotetext{
${ }^{4}$ Vigotski (2000) reporta-se ao exemplo da baleia, apresentado por K. Lewin, que externamente se parece mais com os peixes do que com os mamíferos.

5 Novaes-Pinto discorre nos referidos estudos sobre a análise qualitativa de episódios interativos, segundo a abordagem metodológica de cunho sociocultural, comênfase no estudo da afasia.
} 
de interação, dentre outros, constituem a concepção de linguagem que orienta a formulação de princípios teórico-metodológicos da área. (NOVAES-PINTO, 2012a, b).

A Neurolinguística tem como um dos principais objetos de estudo a afasia. Trata-se de um campo hibrido, constituído pelas Neurociências e pela Linguística, o que explica os confrontos e, às vezes, conflitos de paradigmas (MORATO, 2002). Novaes-Pinto (2012a, b) complementa, afirmando que, apesar de ambas as ciências focalizarem a relação entre cérebro, linguagem e cognição e, deste modo, compartilharem os mesmos objetos de estudo, têm dificuldade em dialogar entre si. $\mathrm{O}$ que mais marca as diferenças entre essas áreas diz respeito à concepção de linguagem que subjaz à descrição e explicação dos fenômenos e influencia de forma direta a metodologia de pesquisa, além da avaliação e conduta terapêutica.

Segundo Novaes-Pinto (2010), tanto as teorias estruturalistas como as gerativistas (em suas diversas versões) influenciaram o desenvolvimento teórico e metodológico da Neurolinguística. No Brasil, essa influência reflete-se principalmente nos meios de divulgação científica como em congressos e revistas especializadas na área de Neuropsicologia, cujos trabalhos são respaldados por resultados baseados em análises estatísticas, por meio da aplicação de baterias de testes neuropsicológicos padronizados. "A padronização é normativa, pautada na língua padrão escrita, e visa estabelecer relações diretas entre um cérebro médio - cuja metáfora atual é a do computador - e a língua como um sistema estável, dissociada de seu uso social" (2010, p. 124, grifo meu). Focalizam-se, nas baterias, questões de ordem metalinguística. A autora segue dizendo que, por outro lado, como também defende Vigotski, as análises de cunho qualitativo podem revelar os aspectos dos processos envolvidos. Isso acaba por contribuir com uma teorização pautada em novos princípios, valorizando "outras formas de razão científica” (NOVAES-PINTO, 2010, p. 14).

Estudos qualitativos têm revelado que o modo como a lesão neurológica impactou a vida de cada sujeito acometido pela afasia, a postura que assumem e como lidam com este impacto, ou seja, questões relativas à visão de mundo e ao sistema de valores singulares encontram-se relacionados às características linguísticas de sujeitos afásicos. Esses dados são relevantes, principalmente, para o acompanhamento terapêutico com esses sujeitos (CAZAROTTI-PACHECO, 2012).

\section{O Paradigma microgenético}

Segundo Wertsch (1985), a tese da constituição cultural dos processos humanos, aliada à importância concedida ao seu desenvolvimento e a preocupação com a dimensão histórica acabam por direcionar a abordagem de Vigotski a vários domínios genéticos, como: a filogênese, a qual se baseia na história da espécie humana; a sociogênese (ou história sociocultural), que procura compreender o indivíduo num mundo cultural; e a ontogênese, que busca entender o percurso do desenvolvimento do indivíduo, desde a infância até a vida adulta. A microgênese é proposta por Vigotski (2003), com vista aos três domínios anteriores.

Para Siegler e Crowley (1991), foram Werner e Vigotski - precursores da psicologia do desenvolvimento - que desenvolveram o conceito de método microgenético. Werner apresentou, no início dos anos 1920, os experimentos genéticos, que buscavam descrever 
os desdobramentos das sucessivas representações que compõem os eventos psicológicos. Seus estudos microgenéticos focalizavam um único estímulo ou uma única sessão de experimento, porém, ele observou que essa abordagem poderia ser aplicada em processos mais longos (horas, dias ou semanas).

Segundo os autores, Vigotski (1978) concordou com a proposta de Werner a respeito dos experimentos genéticos. De modo mais geral, ele argumentou pelo estudo dos conceitos e habilidades no processo de mudança, em oposição ao que se fazia na psicologia experimental, que consistia em se estudar as reações apenas depois de se tornarem "estáveis" e propôs que se observassem as mudanças que ocorrem nas sessões experimentais e entre elas. O desenvolvimento de qualquer processo psicológico "pode limitar-se a poucos segundos, ou mesmo frações de segundos (como no caso da percepção normal). Pode também (como no caso dos processos mentais complexos) durar muitos dias e mesmo semanas"(VIGOTSKI, 2003, p. 81).

Vigotski (2000/1983) aponta, ainda, que para Werner a estrutura psicológica caracteriza-se por várias camadas genéticas que se sobrepõem umas às outras. Deste modo, o estudo genético revela, mesmo no comportamento do indivíduo isolado, determinadas fases genéticas que dizem respeito a processos do desenvolvimento já concluídos. Nas palavras do autor:

Sólo la psicología de los elementos presenta la conducta humana en forma de una esfera única y cerrada. A diferencia de ella, la nueva psicología establece que en la conducta humana existen diversas etapas genéticas. La misión principal de la investigación actual consiste, según Werner, en descubrir las múltiples capas genéticas en el comportamiento del hombre (2000, p. 146).

Portanto, Vigotski (2001, 2003) afirma que, para compreender um processo, é preciso retornar à origem do desenvolvimento de uma determinada estrutura - sua gênese. Ele explorou essa diretriz metodológica voltada para a análise minuciosa de um processo. É nesse sentido que as análises neste paradigma são concebidas como microgenéticas. A fim de complementar a explicação do termo, trago a seguinte passagem de Góes (2000, p.15):

[...] não é micro porque se refere à curta duração dos eventos, mas sim por ser orientada para minúcias indiciais - daí resulta a necessidade de recortes num tempo que tende a ser restrito. É genética no sentido de ser histórica, por focalizar o movimento durante processos e relacionar condições passadas e presentes, tentando explorar aquilo que, no presente, está impregnado de projeção futura. É genética, como sociogenética, por buscar relacionar os eventos singulares com outros planos da cultura, das práticas sociais, dos discursos circulantes, das esferas institucionais.

\section{Discussão}

A atenção às minúcias durante o curso de transformação das ações do sujeito, nos pressupostos histórico-culturais, nada tem a ver com privilegiar elementos isolados. O nível da microanálise se contrapõe ao estudo de elementos e leis de associação e visa à análise por unidades. A unidade é considerada a instância de recorte em que as propriedades do todo 
que se investiga são conservadas, portanto, "a unidade é o componente vivo do todo" (GÓES, 2000, p. 14).

Andrade e Smolka (2011) concordam com a autora e esclarecem que a análise microgenética envolve o plano das interações em termos dos microeventos, os quais dizem respeito ao desenvolvimento cultural humano. Constituem-se como indícios do funcionamento das interações e só podem ser revelados numa análise minuciosa "de modo a configurar sua gênese social e as transformações do curso de eventos" (GÓES, 2000, p. 11).

Existem três principais formas de estudo minucioso em processos interativos: a cognitivista, que focaliza o plano intrapessoal nos eventos interativos; a interacionista, que propõe o exame das relações interpessoais e o jogo conversacional como essenciais para a formação do funcionamento intrapessoal; e a enunciativo-discursiva, a qual busca privilegiar a dimensão dialógica e também relacionar interação, discurso e conhecimento (ROJO, 1997).

A última vertente - enunciativo-discursiva - vem direcionando trabalhos anteriores da autora deste texto (realizados, principalmente, no âmbito do grupo de pesquisas - GELEP ${ }^{6}$ ) e as pesquisas de muitos colegas na área de Neurolinguística, pois além de se relacionar à corrente sócio-histórico-cultural, possibilita o estudo das relações do funcionamento macrossocial, ou seja, nos processos interativos, nas práticas sociais.

Com relação aos estudos voltados ao campo da Linguística, entendemos que a análise microgenética traz a possibilidade de compreender como se deu o impacto das patologias sobre o sistema da língua (nas trocas de palavras, de fonemas, na desorganização sintática) e também com relação aos aspectos pragmáticos e discursivos (circunlóquios, repetições, reformulações) por darem visibilidade às atividades epi- e metalinguísticas em funcionamento durante a produção dos enunciados. A análise microgenética possibilita demonstrar que, a partir de dados singulares, podemos inferir sobre o funcionamento da linguagem tanto na normalidade quanto nas patologias.

Cantarin (2002), ainda a esse respeito, diz que essa análise evita tanto o determinismo biológico (restrito ao campo da filogenética) como o cultural (próprio da ontogênese) e propicia, assim, a total compreensão do indivíduo em suas singularidades durante a situação de mediação. A análise microgenética, como sugere Góes (2000), pode se apresentar como um caminho exclusivo durante uma investigação ou ainda aparecer articulada a outros procedimentos.

A partir de tais premissas, podemos afirmar que a forma de construção de dados nessas pesquisas - por meio de videogravação e transcrição dos episódios - focaliza a atenção aos detalhes, o recorte de episódios interativos, um exame orientado para o funcionamento dos discursos, para as relações intersubjetivas e condições sociais da situação, resultando num relato minucioso dos acontecimentos. O objetivo é a explicação dos fenômenos investigados em detrimento da simples descrição. A microgênese é proposta com vista aos demais domínios genéticos que focalizam o funcionamento linguístico-cognitivo dos sujeitos em todas as dimensões (biológicas, sociais e históricas).

\footnotetext{
${ }^{6}$ O GELEP - Grupo de Estudos da Linguagem no Envelhecimento e nas Patologias, Plataforma Lattes $\mathrm{CNPq}$ - é coordenado pela Profa. Dra Rosana C. Novaes Pinto.
} 
Apresento, a seguir, a análise microgenética de um episódio dialógico com um sujeito afásico - MA, para desenvolver esta discussão. Recorro também a alguns conceitos bakhtinianos - principalmente de enunciado, acabamento e querer-dizer - para auxiliar a análise (NOVAES-PINTO, 1999, 2011; CAZAROTTI-PACHECO; NOVAES-PINTO, 2010, CAZAROTTI-PACHECO, 2012).

MA nasceu em 11/09/1942, é brasileira, viúva, mãe de quatro filhos, artista plástica (pintora de quadros), com ensino médio completo. Teve um episódio de AVC hemorrágico em 2008, após passar por um procedimento de clipagem de dois aneurismas cerebrais no hemisfério esquerdo. Apresenta, em consequência desse episódio, hemiparesia à direita e uma afasia que pode ser mais caracterizada como não-fluente. Sua principal dificuldade é a de encontrar palavras, o que a leva a produzir enunciados com muitas hesitações e com parafasias (fonológicas e semânticas). Frequenta o CCA desde agosto de 2008.

O sujeito MA e sua filha haviam relatado anteriormente a Imp sobre o fato de ela ter sofrido uma queda naquela manhã (11/10/2011). Quando todo o grupo do CCA (Centro de Convivência de Afásicos) ${ }^{7}$ estava reunido, Imp pede para que MA reconte a situação vivenciada. Ainda participaram do episódio: Irn e Itn (interlocutores não-afásicos, assim como Imp).

\footnotetext{
${ }^{7}$ O Centro de Convivência de Afásicos (CCA) nasceu de uma ação conjunta entre os Departamentos de Linguística e de Neurologia da Universidade Estadual de Campinas (UNICAMP), com funcionamento no Instituto de Estudos Linguísticos (IEL), com o objetivo de prover alternativas para as dificuldades enfrentadas pelos sujeitos afásicos, diante do isolamento social que enfrentam com muita frequência, após o acometimento neurológico. O acompanhamento é realizado em grupo, na convivência com sujeitos não afásicos, em diversas situações e práticas discursivas nas quais se exploram todos os aspectos que constituem o funcionamento da linguagem em suas diferentes configurações, como nos diálogos, comentários, narrativas, leituras e etc. (COUDRY, 1988[1986]; NOVAES-PINTO, 2012b).
} 
Quadro 1 ${ }^{8}$ : Episódio dialógico com o sujeito afásico $\mathrm{MA}^{9}$

\begin{tabular}{|c|c|c|c|}
\hline Turno & $\begin{array}{l}\text { Interlo- } \\
\text { cutor }\end{array}$ & Enunciado verbal & Enunciado não-verbal \\
\hline 1 & $\operatorname{Imp}$ & $\begin{array}{l}\text { O que aconteceu hoje cedo, MA? Conta } \\
\text { aí. }\end{array}$ & \\
\hline 2 & MA & Eu... caí. & $\begin{array}{l}\text { Rindo (em seguida, os demais } \\
\text { participantes também riem pelo } \\
\text { modo como MA falou). }\end{array}$ \\
\hline 3 & Irn & Cê calU, aonde? & \\
\hline 4 & MA & Porque e::u... ba-nheiro... tchum. & $\begin{array}{l}\text { Faz gesto com a mão, de baixo } \\
\text { para cima, provavelmente } \\
\text { indicando uma queda. }\end{array}$ \\
\hline 5 & Irn & Durante o banho, MA? & \\
\hline 6 & MA & $\begin{array}{l}\text { Porque tava... tava muito di com lá não } \\
\text { conse/guia. }\end{array}$ & $\begin{array}{l}\text { Faz gesto de abrir a torneira e em } \\
\text { seguida da água caindo. }\end{array}$ \\
\hline 7 & $\operatorname{Imp}$ & Esquentá, né? & \\
\hline 8 & MA & [[Daí depois/ & \\
\hline 9 & $\operatorname{Imp}$ & $\begin{array}{l}\text { [[o seu, né? Fal/exPLIca. O SEu chuveiro, } \\
\text { o SEu banheiro não tava/ }\end{array}$ & \\
\hline 10 & MA & $\begin{array}{l}\text { É e ia do do banheiro daqui, } \\
\text { aqui. }\end{array}$ & $\begin{array}{l}\text { Aponta para uma direção e depois } \\
\text { na direção oposta. }\end{array}$ \\
\hline 11 & Irn & Aí você foi no outro banheiro? & $\begin{array}{l}\text { Faz gesto com a mão indicando } \\
\text { "outro". }\end{array}$ \\
\hline 12 & MA & $\begin{array}{l}\text { E tava, depois, começou a:: a caí } \\
\text { no:: assim no:: }\end{array}$ & $\begin{array}{l}\text { Passa a mão na sua cabeça. Faz } \\
\text { gesto de água caindo e aponta } \\
\text { para baixo. }\end{array}$ \\
\hline 13 & Irn & No cano? & $\begin{array}{l}\text { Faz um gesto indicando algo } \\
\text { longo e fino, provavelmente a } \\
\text { barra onde deve segurar. }\end{array}$ \\
\hline 14 & MA & Não, assim, ali assim... & $\begin{array}{l}\text { Desenha círculos com a mão } \\
\text { voltada para baixo. }\end{array}$ \\
\hline 15 & $\operatorname{Imp}$ & Muito quente? & \\
\hline 16 & Irn & No boxe, dentro do boxe? & \\
\hline 17 & MA & Assim... assim... & $\begin{array}{l}\text { Faz gesto indicando que há um } \\
\text { objeto ao lado de outro. }\end{array}$ \\
\hline
\end{tabular}

(continua)

\footnotetext{
${ }^{8}$ A legenda do quadro encontra-se na seção $\operatorname{ANEXO(S).~}$

${ }^{9} \mathrm{O}$ dado foi extraído da pesquisa de doutorado da autora deste texto (CAZAROTTI-PACHECO, 2012). O episódio videogravado foi transcrito e posteriormente analisado.
} 


\begin{tabular}{|c|c|c|c|}
\hline 18 & Imp & Xampu... o xampu? & \\
\hline 19 & MA & $\begin{array}{l}\text { Isso... calU } \\
\text { aí eu fui e (EI) di, mas ficou... }\end{array}$ & Faz gesto de cair. \\
\hline 20 & Irn & Você escorregou no xamPU, então. & \\
\hline 21 & MA & Daí caí "xum" "tchiuft". & $\begin{array}{l}\text { Faz gesto de cair e sorri (risos } \\
\text { gerais). }\end{array}$ \\
\hline 22 & $\operatorname{Irn}$ & $\begin{array}{l}\text { E machuco::u MA? Tá com dor? } \\
\text { Machucou? }\end{array}$ & \\
\hline 23 & MA & $\begin{array}{l}\text { NO::ssa Senhora, aí ele me dô u::m um } \\
\text { lau/na-gé-sico. }\end{array}$ & \\
\hline 24 & Itn & AnalGÉsico? & \\
\hline 25 & MA & É, e:: passô! & \\
\hline 26 & Irn & $\begin{array}{l}\text { Nossa, mas precisa tomar cuiDAdo hein } \\
\text { gente/ }\end{array}$ & \\
\hline 27 & MA & É. & \\
\hline 28 & Irn & Essa cois a de tom::bo. & \\
\hline 29 & MA & Mas no banheiro... & Faz gesto de misturar algo. \\
\hline 30 & $\operatorname{Imp}$ & $\begin{array}{l}\text { Mas explica MA, no seu banheiro, o que } \\
\text { você colocou, pra ficar mais seguro, no } \\
\text { seu banheiro? }\end{array}$ & \\
\hline 31 & MA & $\begin{array}{l}\text { AH não, LÁ é bem as sim, assim. } \\
\text { Aqui, as sim. }\end{array}$ & $\begin{array}{l}\text { Faz gesto mostrando algo } \\
\text { semelhante a uma barra. Faz gesto } \\
\text { de segurar uma barra. }\end{array}$ \\
\hline 32 & Irn & Ah, tem um um... & \\
\hline 33 & Imp & Barra, né? & \\
\hline 34 & MA & & $\begin{array}{l}\text { Acena positivamente com a } \\
\text { cabeça. }\end{array}$ \\
\hline 35 & Imp & $\begin{array}{l}\text { Mas lá era o banheiro da A. e daí ela não } \\
\text { tem, né? }\end{array}$ & $\begin{array}{l}\text { (Imp explica que era o banheiro da } \\
\text { filha de MA, que não tem a barra } \\
\text { de segurança). }\end{array}$ \\
\hline 36 & MA & $\begin{array}{l}\text { Não nesse. } \\
\text { É. }\end{array}$ & $\begin{array}{l}\text { Acena positivamente com a } \\
\text { cabeça. }\end{array}$ \\
\hline 37 & Imp & No da sua filha não tem, né? Barra. & \\
\hline 38 & MA & É. & \\
\hline
\end{tabular}


O sujeito afásico MA constrói aqui sua narrativa de forma dialógica e é possível identificarmos vários elementos próprios de uma narrativa - resumo, orientação espacial, personagem, fato complicador (inédito), resultado, dentre outros (cf. LABOV; WALETZKY, 1967).

Suas dificuldades linguísticas são evidentes durante toda a construção da narrativa, em especial a dificuldade para selecionar e combinar as unidades linguísticas (cf. JAKOBSON, 1970[1955]), que acaba impactando, por vezes, a construção sintática. Podemos verificálas nas pausas longas e reformulações produzidas, em enunciados ininteligíveis, quando MA não consegue dizer a palavra que deseja. Em alguns momentos fica fácil interpretar o que ela quer contar, mesmo para Irn, que não compartilhava da história de antemão. Como, por exemplo, no turno 10, quando MA diz: É e ia do do banheiro daqui (aponta para uma direção e depois na direção oposta) aqui e no turno seguinte Irn a interpreta adequadamente: Aí você foi no outro banheiro?

Há, no entanto, enunciados de MA que demandam uma maior negociação dos sentidos e, quando isso ocorre, seus interlocutores vão dando sucessivos acabamentos, em geral por meio de perguntas. MA não desiste e passa a apoiar-se nos enunciados de seus parceiros da comunicação verbal (cf. BAKHTIN), como vemos nos turnos de 12 a 21.

O sujeito afásico MA também reelabora/reformula, assim como faz com os enunciados verbais, os de natureza não-verbal, gestual, o que a auxilia a alcançar seu quererdizer (cf. BAKHTIN), pois passa a ser melhor interpretada por seus interlocutores.

No decorrer do episódio narrativo, os sentidos vão sendo negociados e construídos como acontece em toda situação dialógica. Esse é o espaço onde as atividades epilinguísticas (GERALDI, 1997[1990]) ocorrem e se revelam na narrativa de MA pela presença dessas reformulações, repetições, prolongamentos, pausas longas. Contudo, uma análise mais minuciosa mostra, por um lado, que a grande frequência com que elas se apresentam acaba por prejudicar a fluência dos seus enunciados e, por outro, evidenciam que elas são utilizadas como recursos alternativos para contornar suas dificuldades linguísticas. Assim como, os recursos de se apoiar nos enunciados dos seus interlocutores, o uso de gestos e da silabação.

Associado a isso, o episódio revela a dramaticidade de um bom contador de histórias, pois MA se utiliza também da expressividade facial e gestual - apesar de suas dificuldades e de lançar mão de recursos como as onomatopeias ("xum", 'tchum", "tchiuft") -, bem como do uso da entonação enfática (turnos 19, 23 e 31), características do gênero narrativo.

Observamos, também, que esses recursos alternativos e criativos possibilitam que o sujeito afásico apresente uma argumentação, um dos momentos em que sua subjetividade se revela. A argumentação se desenvolve, principalmente, ao final do episódio, quando Irn (turnos 26 e 28) diz que é preciso tomar cuidado com quedas e MA se defende explicando que existe barra de segurança em seu banheiro, no entanto naquele dia ela precisou usar outro banheiro, aonde aconteceu a queda.

\section{Conclusão}


A análise microgenética do processo de construção dessa narrativa nos mostra que os indícios das dificuldades - pausas frequentes, apoio nos enunciados dos outros, repetições e reformulações, dentre outros processos recorrentes - podem tanto revelar os impactos da afasia no funcionamento da linguagem do sujeito afásico, quanto o trabalho que ele realiza com aquilo que ainda está preservado. Espaço em que a subjetividade também se revela. E estas pistas podem, ainda, contribuir na condução do processo terapêutico.

A partir das reflexões desenvolvidas neste estudo teórico-metodológico, que como dissemos faz parte de uma pesquisa mais ampla, concluímos que a análise microgenética possibilita demonstrar que, a partir de dados singulares, é possível inferir sobre o funcionamento da linguagem e sua relação com a memória, por exemplo - no caso do episódio narrativo analisado -, em sujeitos com alguma patologia ou não.

\section{REFERÊNCIAS}

ANDRADE, J. J.; SMOLKA, A. N. B. Relações entre teorias e métodos na pesquisa em ensino de ciências: ressignificações de um percurso. In: VIII Encontro Nacional de Pesquisa em educação em Ciência - ENPEC, Campinas, 2011. Trabalhos completos..., Campinas: UNICAMP, 2011. Disponível em: <www.nutes.ufrj.br/abrapec/viiienpec/resumos/R01631.pdf $>$. Acesso em: 18 set. 2015.

CANTARIN; G. C. M.: A Constituição do Papel de Narrador/Leitor em Crianças na Idade Pré-Escolar: Investigando Efeitos da Leitura de Histórias no Contexto Pedagógico. 2002. Dissertação (Mestrado em Educação) - Programa de Pós-Graduação em Educação, Universidade Metodista de Piracicaba, Piracicaba.

CAZAROTTI-PACHECO, M. O discurso narrativo nas afasias. 2012. 165 f. Tese (Doutorado em Linguística) - Instituto de Estudos da Linguagem, Universidade Estadual de Campinas, Campinas, 2012.

Análise comparativa dos paradigmas microgenético e indiciário: reflexões sobre a metodologia no campo da Neurolinguística. Relatório Científico de Pós-Doutorado Jr. (FAPESP), 2015. $13 \mathrm{f}$.

CAZAROTTI-PACHECO, M.; NOVAES-PINTO, R. C. Aspectos discursivos da narrativa de um sujeito afásico fluente. Estudos Linguísticos, São Paulo, v. 39, n. 2, p. 568-577, mar./ago. 2010. Disponível em: <http://www.gel.org.br>. Acesso em: 02 out. 2011.

COUDRY, M. I. H. Diário de Narciso: discurso e afasia. São Paulo: Martins Fontes, 1988[1986]. $201 \mathrm{p}$.

DAMICO, J. S. et al. Qualitative methods in aphasia research: basic issues. Aphasiology, London, v. 13, n. 9-11, p. 651-665, ago. 1999. Disponível em: <http:/dx.doi.org/10.1080/026870399401786>. Acesso em: 08 ago. 2011.

FREITAS, M. T. A. A abordagem sócio-histórica como orientadora da pesquisa qualitativa. Cadernos de Pesquisa (Fundação Carlos Chagas), São Paulo, v. 1, n. 116, p. 21-40, 2002. 
No fluxo dos enunciados, um convite à pesquisa. In: FREITAS, M. T.; RAMOS, B. Fazer pesquisa na abordagem histórico-cultural: metodologias em construção. Juiz de Fora: Editora UFJF, 2010. p. 7-12.

GERALDI, J. W. Portos de Passagem. São Paulo: Martins Fontes, 1997[1990]. 252 p.

GÓES, M. C. R. de. A abordagem microgenética na matriz histórico-cultural: uma perspectiva para o estudo da constituição da subjetividade. Cadernos Cedes, Relações de ensino: análises na perspectiva histórico-cultural, Campinas, n. 50, p. 9-25, 2000.

JAKOBSON, R. A afasia como um problema linguístico. In: LEMLE, M.; LEITE, Y. (Org.). Novas Perspectivas Lingüísticas. Petrópolis: Ed. Vozes Limitada, 1970[1955]. p. 43-54.

MORATO, E. M. (Org.). Sobre as afasias e os afásicos. Campinas: Editora da UNICAMP, 2002. $62 \mathrm{p}$.

LABOV, W.; WALETZKY, J. Narrative analysis. In: HELM, J. (Ed.). Essays on the Verbal and Visual Arts. Seattle, 1967. p. 12-44.

NOVAES-PINTO, R. C. A contribuição do estudo discursivo para uma análise crítica das categorias clínicas. 1999. 273 f. Tese (Doutorado em Linguística) - Instituto de Estudos da Linguagem, Universidade Estadual de Campinas. Campinas.

Desafios metodológicos da pesquisa em Neurolinguística no início do século XXI. Revista Estudos Linguísticos, v. 40, 2011b. p. 311-318.

Cérebro, linguagem e funcionamento cognitivo na perspectiva sócio-histórico-cultural: inferências a partir do estudo das afasias. Letras de Hoje: Linguagem e cognição - interfaces entre Linguística, Psicologia e Neurociências. Porto Alegre, v. 47, n. 1, p. 55-64, jan./mar. 2012a. Disponível em: <http $/ /$ www.revistaseletronicas.pucrs.br/index.php/>. Acesso em: 01 mar. 2012.

A social cultural-approach to aphasia: contributions from the work developed at a center for aphasic subjects. In: TAN, Ü. (Ed.). Latest Findings in Intellectual and Developmental Disabilities Research, Croatia, 2012b, p. 219-244. Disponível em: $<\mathrm{http} / /$ www.intechopen.com/articles/show/title/a-social-cultural-approach-to-aphasiacontributions-from-the-work-developed-at-a-center-for-aphasic>. Acesso em: 01 mar. 2012.

PEREIRA, M. L. Blogs literários no trabalho com professoras de Língua Portuguesa: as possibilidades de palavras e contrapalavras. In: FREITAS, M. T.; RAMOS, B. S. (Org.). Fazer pesquisa na abordagem histórico-cultural: metodologias em construção. Juiz de Fora: Editora UFJF, 2010. p. 53-70.

ROJO, R. H. R. Enunciação e interação na ZDP: do "non sense" à construção dos gêneros de discurso. In: Encontro sobre teoria e pesquisa em ensino de ciências - Linguagem, Cultura e Cognição, 1997, Belo Horizonte. Anais... Belo Horizonte: UFMG, 1997. p. 95-109.

SIEGLER, R. S.; CROWLEY, K. (1991). The microgenetic method. American Psychologist, 46 (6), p. 606-620.

VIGOTSKI, L. S. Obras Escogidas: v. 3. Problemas Del desarollo de la psique. Madrid, España: Visor, 2000. 381 p. 
. A construção do pensamento e da Linguagem. Tradução de Paulo Bezerra. São Paulo: Martins Fontes, 2001. 491 p.

A formação social da mente: o desenvolvimento dos processos psicológicos superiores. Tradução de José Cipolla Neto; Luís Silveira Menna Barreto; Solange Castro Afeche. 6. ed. 6. tiragem. São Paulo: Martins Fontes, 2003. 181 p.

WERTSCH, J. V. Vygotsky and the social formation of mind. Cambridge, Mass: Harvard University Press, 1985. 262 p.

Recebido em: 23/09/2015

Aprovado em: 06/05/2016

\section{ANEXO}

Legenda (Quadro 1: Episódio dialógico com o sujeito afásico MA)

\begin{tabular}{|l|l|}
\hline Letras maiúsculas & Mudança de entonação, ênfase \\
\hline , (vírgula) & Pausa de curta duração \\
\hline ... (reticências) & Pausa de longa duração \\
\hline$\left(\right.$ El) $\mathbf{1 0}^{\mathbf{1 0}}$ & Enunciado ininteligível \\
\hline [[ & Sobreposição de vozes \\
\hline- & Silabação \\
\hline I & Interrupção da fala, truncamento \\
\hline$::$ & Alongamento de vogal \\
\hline$($ ) & Observações e comentários quanto às condições de produção \\
\hline
\end{tabular}

10 Nos estudos dos fenômenos afásicos têm-se usado nas transcrições: (SI) para "Segmentos Ininteligíveis". Porém, usaremos - como em trabalhos anteriores - (EI) os quais designam "Enunciados Ininteligíveis", configurando melhor as concepções teóricas deste estudo, sugerido nos trabalhos de Novaes-Pinto. 